\title{
Correlation between Intracellular Accumulation of Peptidoglycan Precursors and Streptomycin Formation
}

\author{
Osamu Nimi, Hiroki Kawashima, Masanori SugIYama \\ and Ryosaku Nomi \\ Department of Fermentation Technology, Faculty of Engineering, \\ Hiroshima University, Shitami, Saijocho, Higashihiroshima 724, Japan
}

Received July 11, 1983

\begin{abstract}
When the mycelium of Streptomyces griseus HUT 6037 was suspended in $0.5 \% \mathrm{NaCl}$ solution containing ${ }^{14} \mathrm{C}$-glucosamine, peptidoglycan precursors accumulated in the cells. While UDP- $N$ acetylglucosamine accumulated in the largest amount among the precursors, extracellularly added and intracellularly accumulated UDP- $N$-acetylglucosamine were not used to synthesize streptomycin and were probably used for peptidoglycan formation.

On the other hand, correlation was recognized between accumulation of glucosamine-6phosphate $(\mathrm{GlcN}-6 \mathrm{P})$ and streptomycin formation. Addition of an inhibitor of peptidoglycan synthesis such as enduracidin, vancomycin or cycloserine to a mycelium-suspended culture changed the ratio of accumulated peptidoglycan precursors. When streptomycin formation was stimulated by addition of enduracidin or vancomycin, intracellular GlcN-6P remarkably increased and then decreased rapidly. On the contrary, when cycloserine was added to the culture, no increase of GlcN$6 \mathrm{P}$ was observed and streptomycin formation was not stimulated. These results suggest that an increase in the intracellular concentration of GlcN-6P is required for activation or induction of the system for utilizing GlcN-6P for streptomycin formation.
\end{abstract}

It has been reported that the production of aminoglycoside antibiotics such as streptomycin, ${ }^{1)}$ neomycin, ${ }^{2)}$ kanamycin ${ }^{3)}$ and sagamicin $^{4)}$ was enhanced by suppression of cell wall peptidoglycan synthesis of the producers. These stimulative effects on antibiotic production suggested that utilization of a cell wall precursor was shunted toward antibiotic formation by a regulatory mechanism when cell wall synthesis was suppressed. It is already known that the precursors of peptidoglycan synthesis accumulate in the cell by inhibiting the biosynthesis. Therefore, the regulatory mechanism for the formation of an antibiotic will be elucidated by studying the correlation between the accumulation of peptidoglycan precursors and the formation of the antibiotic.

In our previous paper, ${ }^{5)}$ the substances which accumulated in the cells of Streptomyces griseus HUT 6037 were investigated under the condition that streptomycin production was stimulated by suppression of cell wall synthesis by antibiotics. The major substances accumulated were UDP- $N$-acetylmuramyl-pentapeptide (UDP-MurNAc-pentapeptide), UDPMurNAc-dipeptide, UDP- $N$-acetylglucosamine (UDP-GlcNAc), $N$-acetylglucosamine-1-phosphate, glutamic acid and trehalose. The former four substances are the precursors of peptidoglycan.

The present investigation was performed to determine which peptidoglycan precursor was specifically related to stimulation of streptomycin production when it was accumulated in the cells.

\section{MATERIALS AND METHODS}

Microorganisms and growth conditions. Streptomyces griseus HUT 6037 was used throughout this study. The culture was grown under reciprocal shaking at $28^{\circ} \mathrm{C}$ in a $500 \mathrm{ml}$ shaking flask with $100 \mathrm{ml}$ of a medium containing $25 \mathrm{~g}$ glucose, $2 \mathrm{~g}\left(\mathrm{NH}_{4}\right)_{2} \mathrm{SO}_{4}, 0.4 \mathrm{~g} \mathrm{KH}_{2} \mathrm{PO}_{4}, 1 \mathrm{~g} \mathrm{NaCl}, 6 \mathrm{~g}$ 
$\mathrm{K}_{2} \mathrm{SO}_{4}, 0.2 \mathrm{~g} \mathrm{MgSO}_{4} \cdot 7 \mathrm{H}_{2} \mathrm{O}, 0.01 \mathrm{~g} \mathrm{FeSO}_{4} \cdot 7 \mathrm{H}_{2} \mathrm{O}, 0.05 \mathrm{~g}$ $\mathrm{ZnSO}_{4} \cdot 7 \mathrm{H}_{2} \mathrm{O}, 1 \mathrm{~g} \mathrm{CaCO}_{3}$ and $7 \mathrm{~g} \mathrm{~L}^{2}$-asparagine per liter, $\mathrm{pH}$ 7.0. The mycelium for a suspended culture was harvested at the exponential phase of growth $(48 \mathrm{hr}$ at $28^{\circ} \mathrm{C}$ ) unless otherwise stated. After washing with $0.5 \%$ $\mathrm{NaCl}$ solution, the mycelium was diluted with $0.5 \% \mathrm{NaCl}$ solution to give 24 to $27 \mathrm{mg}$ dry weight per milliliter. This washed mycelium preparation was used to prepare a mycelium-suspended culture by dilution with $0.5 \% \mathrm{NaCl}$ solution which contained additives if necessary.

Determination of radioactivity incorporated from $\mathrm{D}-[1$ ${ }^{14}$ C]glucosamine into peptidoglycan and streptomycin. Preparation and determination of peptidoglycan and streptomycin were done according to the method described previously. ${ }^{6 \text { ) }}$

Detection of the substances labeled with $\mathrm{D}^{14} C$ glucosamine in the cells. The method of Strominger ${ }^{7)}$ was used with some modifications for extraction and separation of peptidoglycan precursors accumulated in the cells. To a mycelium suspension which contained about $5 \mathrm{mg}$ dry weight mycelium per $\mathrm{ml}$ of $0.5 \% \mathrm{NaCl}$ was added $\mathrm{D}-\left[1-{ }^{14} \mathrm{C}\right]$ glucosamine to a final concentration of $0.1 \mu \mathrm{Ci} / \mathrm{ml}$. After shaking for a fixed time, $3.5 \mathrm{ml}$ of the suspension was taken out and centrifuged at $4500 \mathrm{~g}$ for 2 $\mathrm{min}$. The mycelial mass was washed twice with $3 \mathrm{ml}$ of cold water, and then extracted with water at $100^{\circ} \mathrm{C}$ for $10 \mathrm{~min}$. After cooling quickly, cold trichloroacetic acid (TCA) was added to $5 \%$ final concentration. The mixture was kept at $0^{\circ} \mathrm{C}$ for more than $1 \mathrm{hr}$ and then filtered with a glass filter (Whatman $\mathrm{GF} / \mathrm{C}, 25 \mathrm{~mm}$ diameter). The mycelial residue on the filter paper was used for the preparation of peptidoglycan. To the filtrate, the same volume of ethyl ether was added and shaken vigorously for removal of TCA, then the ethyl ether layer was discarded. This procedure was repeated three times. The water layer was heated in a hot water bath to remove the residual ethyl ether, and then dried in vacuo after adjusting to $\mathrm{pH}$ 7.0. The residue was dissolved in $50 \mu \mathrm{l}$ water. A $1 \mu \mathrm{l}$ portion was subjected to two dimensional paper chromatography (Whatman $20 \mathrm{Chr}$.). The solvent system of isobutyric acid- $0.5 \mathrm{~N} \mathrm{NH}_{4} \mathrm{OH}(5: 3$ by volume) was used for the first dimension and ethanol- $0.5 \mathrm{~N}$ ammonium acetate $(7.5: 3)$ for the second. The radioactive substances were detected by radioautography, 7 days exposure to Fuji $\mathrm{X}$ ray film (KX medical). The radioactivity of each substance on paper was determined with a liquid scintillation counter using the paper piece which was cut out from the corresponding part on the paper chromatogram.

Uptake of ${ }^{14} \mathrm{C}$-glucosamine into mycelium. A half milliliter of washed mycelium was mixed in a test tube with ${ }^{14} \mathrm{C}$-glucosamine $(6.5 \mu \mathrm{Ci} / \mathrm{ml}$ mycelium suspension $)$ and $2 \mathrm{ml}$ of $0.5 \% \mathrm{NaCl}$ solution prewarmed at $28^{\circ} \mathrm{C}$. This mixture was shaken at $120 \mathrm{rev} / \mathrm{min}$. A $200 \mu \mathrm{l}$ portion taken from the culture at a given time was filtered through a glass filter (Whatman $\mathrm{GF} / \mathrm{F}$ ), followed by immediate washing with $10 \mathrm{ml}$ of ice-cold $100 \mathrm{~mm} \mathrm{Na} \mathrm{SO}_{4}$ dissolved in $0.5 \%$ saline. After drying the filter, the radioactivity was measured with a liquid scintillation counter.

\section{RESULTS}

\section{Identification of ${ }^{14} \mathrm{C}$-labeled precursors of pep- tidoglycan derived from ${ }^{14} \mathrm{C}$-glucosamine}

When $\mathrm{D}-\left[1-{ }^{14} \mathrm{C}\right]$ glucosamine was added to a mycelium-suspended culture, ${ }^{14} \mathrm{C}$-labeled substances accumulated in the cells. Some of these labeled substances were determined in the previous study. ${ }^{5)}$ In this study, to elucidate the biosynthetic correlation between streptomycin formation and intracellular accumulation of peptidoglycan precursors, the accumulated precursors were examined in detail by radioautography of two dimensional paper chromatograms. The radioactivities of spots on radioautograms varied depending on the incubation time and addition of inhibitors of cell wall synthesis. All of the spots which appeared on the radioautograms in the present investigation are shown together in Fig. 1.

Identification of the spots was reported in the previous paper except for that of spots 1 and 5. Spot 1 appeared to be UDP-MurNActripeptide from the fact that the $R f$ value was

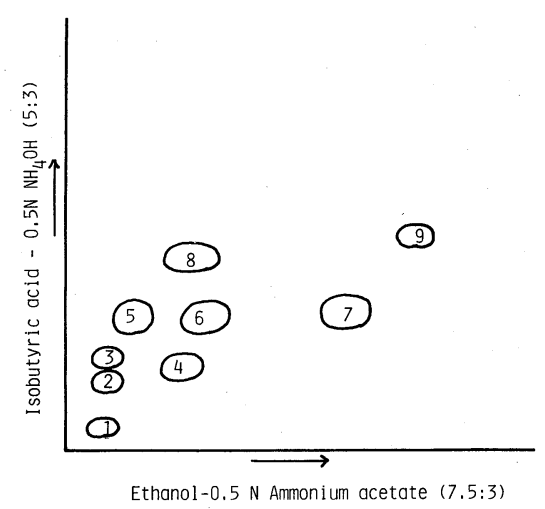

FIG. 1. Paper Radioautogram of Intracellular Radioactive Substances Produced on Addition of ${ }^{14} \mathrm{C}$-Glucosamine to Mycelium-suspended Cultures.

1, UDP-MurNAc tripeptide; 2, UDP-MurNAc pentapeptide; 3, UDP-MurNAc dipeptide; 4, UDP-GlcNAc; 5 , glucosamine-6-phosphate; $6, \mathrm{~N}$-acetylglucosamine-1phosphate; 7, trehalose; 8, glutamic acid; 9, not determined. 
lower than that of UDP-MurNAc-pentapeptide and the same as that of UDP-MurNAc-tripeptide with the same solvent system as used by Ito and Strominger. ${ }^{8)}$

Spot 5 was cut out from the paper chromatogram, extracted with water and concentrated. The concentrate gave glucosamine on incubation with alkaline phosphatase of Escherichia coli. Two dimensional co-chromatography of the concentrate with authentic glucosamine-6-phosphate (Sigma) using the solvent systems described in MATERIALS AND Methods gave only one spot with a positive Elson-Morgan reaction and radioactivity. Thus spot 5 was identified as glucosamine-6phosphate.

\section{Variation in accumulation of peptidoglycan precursors}

It was reported previously ${ }^{6)}$ that the stimulative effect of enduracidin on incorporation of ${ }^{14} \mathrm{C}$-glucosamine into streptomycin was remarkable in mycelia at the middle $(36 \mathrm{hr})$ and late $(43 \mathrm{hr})$ logarithmic phases of growth, but not in mycelia older than the transient phase $(50 \mathrm{hr})$. In mycelium-suspended cultures using mycelia of these different ages, the radioactivity incorporated from ${ }^{14} \mathrm{C}$-glucosamine into peptidoglycan precursors which accumulated after 15 min incubation was determined with addition and non-addition of enduracidin. The results are shown in Table I.

UDP-GlcNAc was accumulated in the largest amount among the peptidoglycan intermediates at all ages of the mycelia used. No stimulative effect of enduracidin on accumulation was observed. On the other hand, the amount of glucosamine-6-phosphate remarkably increased on addition of enduracidin to the mycelia from the middle and late logarithmic phases of growth, but this was not the case in the mycelium from the transient growth phase. Accumulation of GlcNAc-1-phosphate was analogous to that of glucosamine-6phosphate but the increase on addition of enduracidin was less than that of glucosamine6-phosphate.

\section{Possibility of UDP-GlcNAc being a strepto- mycin precursor}

When UDP-GlcNAc is added to a mycelium suspension, it may be cleaved into uridinephosphate and $\mathrm{N}$-acetyl-glucosamine before uptake into the mycelium. Then, by adding UDP- $N$-acetyl-[U- $\left.{ }^{14} \mathrm{C}\right]$ glucosamine or $\mathrm{N}$ acetyl- $\left[1-{ }^{14} \mathrm{C}\right] \mathrm{glucosamine}$ to mycelium-suspended cultures, intracellular radioactive substances were compared after incubation for

Table I. Influence of Mycelial Age and Enduracidin on Accumulation of Peptidoglycan Precursors in Resting Mycelium of S. griseus $^{a}$

\begin{tabular}{|c|c|c|c|c|c|c|}
\hline \multirow{3}{*}{ Precursors } & \multicolumn{6}{|c|}{ Ratio of accumulated peptidoglycan precursors $(\%)^{b}$} \\
\hline & \multicolumn{2}{|c|}{ Middle logarithmic phase } & \multicolumn{2}{|c|}{ Late logarithmic phase } & \multicolumn{2}{|c|}{ Transient phase } \\
\hline & $\begin{array}{l}\text { Without } \\
\text { antibiotic }\end{array}$ & Enduracidin & $\begin{array}{l}\text { Without } \\
\text { antibiotic }\end{array}$ & Enduracidin & $\begin{array}{l}\text { Without } \\
\text { antibiotic }\end{array}$ & Enduracidin \\
\hline UDP-GlcNAc & 65 & 47 & 66 & 55 & 65 & 66 \\
\hline UDP-MurNAc-pentapeptide & 15 & 12 & 9 & 5 & 9 & 8 \\
\hline UDP-MurNAc-dipeptide & 13 & 4 & 8 & 7 & 7 & 7 \\
\hline $\begin{array}{l}N \text {-Acetylglucosamine- } \\
\text { 1-phosphate }\end{array}$ & 4 & 9 & 8 & 10 & 5 & 5 \\
\hline Glucosamine-6-phosphate & 3 & 28 & 9 & 23 & 14 & 14 \\
\hline
\end{tabular}

a Washed mycelium was prepared respectively from $36 \mathrm{hr}$ (middle logarithmic), $43 \mathrm{hr}$ (late logarithmic) and $50 \mathrm{hr}$ (transient growth phase). $1.6 \mathrm{ml}$ of washed mycelium was suspended in $6.4 \mathrm{ml}$ of $0.5 \% \mathrm{NaCl}$ or $0.5 \% \mathrm{NaCl}$ containing $800 \mu \mathrm{g}$ of enduracidin. The suspension was incubated at $28^{\circ} \mathrm{C}$ after addition of ${ }^{14} \mathrm{C}$-glucosamine $(0.3 \mu \mathrm{Ci} / \mathrm{ml})$. After $15 \mathrm{~min}$ incubation, the radioactivity incorporated into peptidoglycan precursors was determined.

b Total radioactivity of peptidoglycan precursors accumulated was taken as $100 \%$. 


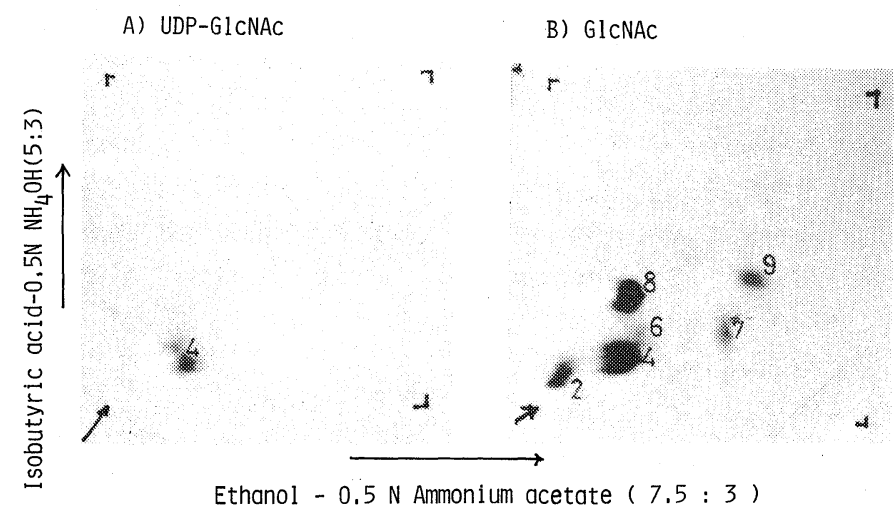

FIG. 2. Paper Radioautograms of Intracellular Radioactive Substances Produced on Addition of UDP- $N$ Acetyl-[U- $\left.{ }^{14} \mathrm{C}\right]$ glucosamine or $\mathrm{N}$-Acetyl- $\left[1-{ }^{14} \mathrm{C}\right]$ glucosamine to Mycelium-suspended Cultures.

UDP- $N$-Acetyl-[U- $\left.{ }^{14} \mathrm{C}\right]$ glucosamine or $N$-acetyl-[1- $\left.{ }^{14} \mathrm{C}\right]$ glucosamine $(0.3 \mu \mathrm{Ci} / \mathrm{ml}, 6.5 \mu \mathrm{Ci} / \mu \mathrm{mol})$ was added to $8 \mathrm{ml}$ of mycelium suspension. After incubation at $28^{\circ} \mathrm{C}$ for $30 \mathrm{~min}$, intracellular substances accumulated in the mycelium were determined as described in MATERIALS AND Methods. Spot numbers are the same as in Fig. 1.

TABLE II. INCORPORATION OF UDP- $N$-Acetyl-[U- $\left.{ }^{14} \mathrm{C}\right]$ glucosamine and $N$-Acetyl-[1- $\left.1{ }^{14} \mathrm{C}\right]-$ glucosamine into Streptomycin ANd Cell Wall Peptidoglycan ${ }^{a}$

\begin{tabular}{|c|c|c|c|}
\hline & \multicolumn{2}{|c|}{ Radioactivity incorporated (cpm) } & \multirow{2}{*}{$\mathrm{A} / \mathrm{B}$} \\
\hline & Streptomycin (A) & Peptidoglycan (B) & \\
\hline UDP- $N$-Acetyl-[U- $\left.{ }^{14} \mathrm{C}\right]$ glucosamine & 12 & 4,044 & 0.003 \\
\hline$N$-Acetyl-[1- $\left.{ }^{14} \mathrm{C}\right]$ glucosamine & 4,423 & 49,350 & 0.09 \\
\hline
\end{tabular}

$30 \mathrm{~min}$ at $28^{\circ} \mathrm{C}$. The dose of both radioactive additives was $0.3 \mu \mathrm{Ci}$ per $\mathrm{ml}$ of mycelium suspension.

As shown in Fig. 2, when UDP- $N$-acetyl-[U${ }^{14}$ Clglucosamine was added, only UDPGlcNAc in mycelium was labeled with ${ }^{14} \mathrm{C}$ (Fig. 2A), while several ${ }^{14} \mathrm{C}$-labeled substances were found on addition of $N$-acetyl- $\left[1-{ }^{14} \mathrm{C}\right]$ glucosamine (Fig. 2B). If UDP- $\left[{ }^{14} \mathrm{C}\right]-$ GlcNAc is cleaved outside the mycelium and $\left[{ }^{14} \mathrm{C}\right] \mathrm{GlcNAc}$ is taken into the mycelium, Fig. 2A should show the same pattern as Fig. $2 \mathrm{~B}$, but this was not the case. Thus, the results seemed to indicate that UDP-GlcNAc was taken into the mycelium as it was. However, the uptake of UDP-GlcNAc into mycelium was so low in quantity that ${ }^{14} \mathrm{C}$-labeled strep- tomycin could not be detected.

Then in order to increase the uptake of ${ }^{14} \mathrm{C}$ labeled compounds, UDP- $N$-acetyl-[U- $\left.{ }^{14} \mathrm{C}\right]-$ glucosamine and $N$-acetyl-[1- $\left.{ }^{14} \mathrm{C}\right]$ glucosamine were added to mycelium suspensions after $45 \mathrm{~min}$ preincubation at $28^{\circ} \mathrm{C}$ and the cultures were kept for a further $60 \mathrm{~min}$ with shaking. The doses of radioactive additives were the same as above. The radioactivity incorporated into streptomycin and peptidoglycan was determined as shown in Table II. Incorporation of radioactivity from UDPGlcNAc into peptidoglycan was less than that from $\mathrm{N}$-acetylglucosamine and incorporation into streptomycin was negligible. On the other hand, $N$-acetylglucosamine was incorporated significantly into both streptomycin and pep- 

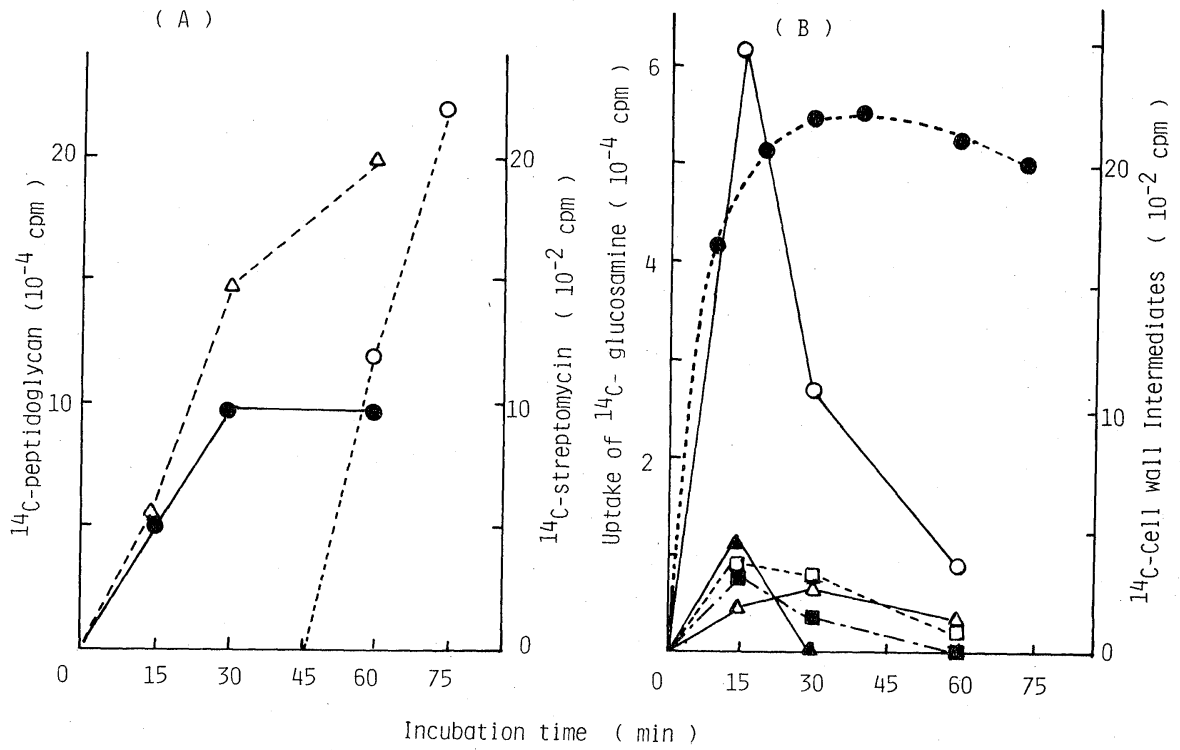

FIG. 3. Time Course of Accumulation of ${ }^{14} \mathrm{C}$-Labeled Peptidoglycan and Its Precursors in Mycelium and Production of ${ }^{14} \mathrm{C}$-Labeled Streptomycin in a Mycelium-suspended Culture with Added D- $\left[1-{ }^{14} \mathrm{C}\right]-$ Glucosamine.

In $A: \triangle$, peptidoglycan; - streptomycin; $\bigcirc$, streptomycin produced by mycelium preincubated for $45 \mathrm{~min}$. In $\mathrm{B}$ : e, uptake of ${ }^{14} \mathrm{C}$-glucosamine into mycelium; $O$, UDP-GlcNAc; $\mathrm{a}$, $N$-acetyl-glucosamine-1phosphate; $\square$, UDP-MurNAc-dipeptide; $\triangle$, UDP-MurNAc pentapeptide;

A, glucosamine-6-phosphate.

tidoglycan. These results indicated that UDPGlcNAc taken up by mycelium was used predominantly for peptidoglycan synthesis and not for streptomycin formation, while $\mathrm{N}$ acetylglucosamine could be a common precursor for streptomycin and peptidoglycan.

\section{Correlation between accumulation of peptido-} glycan precursors and streptomycin formation

To make sure of the above results in respect to the non-availability of UDP-GlcNAc for streptomycin formation and to determine which peptidoglycan precursor is the practical precursor of streptomycin, intracellular peptidoglycan precursors were labeled with ${ }^{14} \mathrm{C}$ glucosamine and the changes of their radioactivities during incubation were followed in connection with streptomycin formation.

To a mycelium suspension $(18 \mathrm{ml})$ was added $\mathrm{D}-\left[1-{ }^{14} \mathrm{C}\right]$ glucosamine at a dose of $0.3 \mu \mathrm{Ci}$ per $\mathrm{ml}$ of suspension. At indicated times, the radioactivity taken up into mycelium as well as that incorporated into peptidoglycan, strepto- mycin and precursors of peptidoglycan were determined. The results are shown in Fig. 3.

The amount of ${ }^{14} \mathrm{C}$-glucosamine taken into mycelium reached the saturation level after 30 min incubation and roughly the same concentration level was maintained for $75 \mathrm{~min}$ (Fig. 3B). On the other hand, while incorporation of radioactivity into streptomycin and peptidoglycan increased for $30 \mathrm{~min}$, the incorporation in streptomycin stopped after 30 min and that into peptidoglycan still increased after $30 \mathrm{~min}$ (Fig. 3A). Accumulation of UDPGlcNAc was the highest at $15 \mathrm{~min}$, showing a rapid decrease thereafter (Fig. 3B). Of these results, the increase in peptidoglycan from 30 to $60 \mathrm{~min}$ (Fig. 3A) seemed to reflect well the decrease in UDP-GlcNAc during the same period (Fig. 3B). Then it seems likely that UDP-GlcNAc was predominantly utilized for peptidoglycan synthesis and not for streptomycin formation. However, there remains the possibility that streptomycin-synthesizing activity of the resting mycelium might have been 
TABle III. INFLUENCES OF VANCOMYCIN AND CyCloserine ON ACCumulation OF Peptidoglycan Precursors in Resting Mycelium of S. griseus $^{a}$

\begin{tabular}{lcccc}
\hline & \multicolumn{2}{c}{ Ratio of accumulated peptidoglycan precursors $(\%)^{b}$} \\
\cline { 2 - 5 } \multicolumn{1}{c}{ Precursors } & $\begin{array}{c}\text { Without } \\
\text { antibiotic }\end{array}$ & Vancomycin & $\begin{array}{c}\text { Without } \\
\text { antibiotic }\end{array}$ & Cycloserine \\
\hline UDP-GlcNAc & 61 & 62 & 71 & 64 \\
UDP-MurNAc-pentapeptide & 13 & 9 & 7 & 4 \\
UDP-MurNAc-dipeptide & 14 & 5 & 7 & 2 \\
UDP-MurNAc-tripeptide & 0 & 0 & 1 & 15 \\
$N$-Acetylglucosamine-1-phosphate & 9 & 11 & 7 & 8 \\
Glucosamine-6-phosphate & 3 & 13 & 7 & 7 \\
\hline
\end{tabular}

a Vancomycin or cycloserine and $\left[1-{ }^{14} \mathrm{C}\right]$ glucosamine were added to mycelium-suspended cultures. After incubation at $28^{\circ} \mathrm{C}$, radioactivities in the peptidoglycan precursors accumulated were determined.

$b$ Total radioactivity of peptidoglycan precursors was taken as $100 \%$.

lost after $30 \mathrm{~min}$ incubation. Then, ${ }^{14} \mathrm{C}$ glucosamine was added to a mycelium suspension after 45 min preincubation and incorporation of radioactivity into streptomycin was determined. As is shown in Fig. 3A, streptomycin-synthesizing activity evidently remained even after 45 min incubation.

It was also noticeable that a significant amount of glucosamine-6-phosphate was accumulated in the mycelium after $15 \mathrm{~min}$ incubation which disappeared during the subsequent $15 \mathrm{~min}$ (Fig. 3B) as if it reflected the increase of streptomycin formation during the same period (Fig. 3A).

\section{Difference in effect of vancomycin and cyclo- serine on accumulation of peptidoglycan precursors}

Streptomycin production in a myceliumsuspended culture was stimulated by enduracidin or vancomycin, but not by cycloserine. ${ }^{6}$ ) These results suggested that the stimulative effect of antibiotics on streptomycin production could be ascribed to accumulation of specific precursor of peptidoglycan in the mycelium because these antibiotics inhibited a different step of peptidoglycan biosynthesis. This led us to investigate the differences in substances accumulated in mycelium by action of vancomycin and cycloserine. Vancomycin $(800 \mu \mathrm{g} / \mathrm{ml})$ or cycloserine $(100 \mu \mathrm{g} / \mathrm{ml})$ were added together with $\mathrm{D}-\left[1-{ }^{14} \mathrm{C}\right]$ glucosamine $(0.3$ $\mu \mathrm{Ci} / \mathrm{ml})$ to $13 \mathrm{ml}$ of mycelium-suspended culture, incubating at $28^{\circ} \mathrm{C}$. After $15 \mathrm{~min}$, the precursor of peptidoglycan accumulated in the mycelium were determined (Table III). By addition of vancomycin, increase in accumulation of glucosamine-6-phosphate were recognized, but no influence on UDP-MurNActripeptide was observed. In the case of cycloserine, a remarkable increase of UDPMurNAc-tripeptide occurred while no influence was observed on the amount of glucosamine-6-phosphate. These results suggest that the increase of glucosamine-6phosphate in mycelium is necessary for stimulation of streptomycin formation.

\section{DISCUSSION}

When resting mycelium of $S$. griseus was suspended and shaken in $0.5 \% \mathrm{NaCl}$ solution, UDP-MurNAc-pentapeptide, UDP-MurNAc-dipeptide, UDP-GlcNAc, $N$-acetylglucosamine-1-phosphate and glucosamine-6phosphate accumulated in the mycelium. Addition of enduracidin or vancomycin to the suspension increased the accumulation of glucosamine-6-phosphate, being accompanied by suppression of peptidoglycan synthesis and stimulation of streptomycin production. ${ }^{6}$ Addition of cycloserine caused no accumulation of glucosamine-6-phosphate, being accompanied by suppression of pep- 
tidoglycan synthesis to some extent and no stimulation of streptomycin production. ${ }^{6)}$

In the present investigation, accumulation of UDP-MurNAc-tripeptide and UDPMurNAc-pentapeptide seemed to have no correlation with streptomycin formation. But circumstantial evidence was obtained for a positive correlation between accumulation of glucosamine-6-phosphate and streptomycin formation. Not only glucosamine-6-phosphate and streptomycin formation ${ }^{6)}$ were enhanced by addition of enduracidin and vancomycin, but also the change of intracellular concentration of glucosamine-6-phosphate reflected streptomycin formation from glucosamine-6phosphate. Though streptomycin precursors are not thought to be only glucosamine-6phosphate, we have already reported that extracellular glucosamine was incorporated into the $N$-methyl-L-glucosamine and streptose moieties of the streptomycin molecule. ${ }^{1,6)}$

It is also very conceivable from the above circumstantial evidence that accumulation of glucosamine-6-phosphate leads to activation (or induction) of a system for utilizing glucosamine-6-phosphate for streptomycin synthesis. There has been no investigation of this problem at enzyme level, so it would be interesting to determine what is the next step of utilization of glucosamine-6-phosphate for streptomycin synthesis. Hirose-Kumagai et $a l{ }^{12)}$ reported that the addition of thymine to a culture of $S$. griseus stimulated the incorporation of D-glucosamine into the $N$-methyl-Lglucosamine moiety and that UDP- $N$-methylD-glucosamine-phosphate was a possible intermediate of the $N$-methyl-L-glucosamine moiety of streptomycin.

\section{REFERENCES}

1) O. Nimi, A. Kokan, K. Manabe, K. Maehara and R. Nomi, J. Ferment. Technol., 54, 587 (1976).

2) I. Szabo, Gy. Barabas and G. Szabo, Biol. Actinomycetes, 12, 28 (1977).

3) K. Basak and S. K. Majumdar, Folia Microbiol., 21, 43 (1976).

4) K. Nakayama, Amino acid, Nucleic acid, 36, 1 (1977).

5) O. Nimi, Y. Amano, A. Ikeda, Y. Yoshimura, M. Sugiyama and R. Nomi, Agric. Biol. Chem., 48, 285 (1984).

6) O. Nimi, H. Kawashima, A. Ikeda, M. Sugiyama and R. Nomi, J. Ferment. Technol., 59, 91 (1981).

7) J. L. Strominger, J. Biol. Chem., 234, 1520 (1973).

8) E. Ito and J. L. Strominger, J. Biol. Chem., 248, 3131 (1973).

9) R. G. Anderson, L. J. Douglas, H. Hussey and L. Baddiley, Biochem. J., 136, 871 (1973).

10) M. Matsuhashi, I. Ohara and Y. Yoshiyama, Agric. Biol. Chem., 33, 134 (1969).

11) F. C. Neuhaus and J. L. Lynch, Biochem. Biophys. Res. Commun., 8, 377 (1962).

12) A. Hirose-Kumagai, A. Yagita and N. Akamatsu, $J$. Antibiot., 35, 1571 (1982). 